\title{
Prophylactic chemotherapeutic hyperthermic intraperitoneal perfusion reduces peritoneal metastasis in gastric cancer: a retrospective clinical study
}

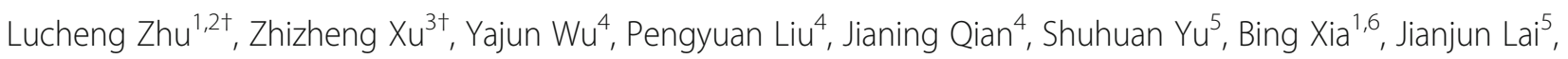
Shenglin $\mathrm{Ma}^{2^{*}}$ and Zhibing $\mathrm{Wu}^{5^{*}}$

\begin{abstract}
Background: Peritoneal metastasis is the most frequent failure in gastric cancer. This study evaluated the role of prophylactic chemotherapeutic hyperthermic intraperitoneal perfusion (CHIP) in patients after D2 dissection.

Methods: Gastric cancer patients after D2 dissection were enrolled in this study. Patients received either chemotherapy (IV group) or CHIP (CHIP group). Sites of recurrence or metastasis, disease-free survival (DFS), overall survival (OS) and adverse events were evaluated.

Results: Twenty-two patients received CHIP treatment, and 21 patients received chemotherapy alone. The median DFS time was 24.5 and 36.5 months in the IV group and CHIP group $(P=0.044)$, respectively. The median OS time was 33.1 months in the IV group and not reached in the CHIP group $(P=0.037)$. We also found that CHIP could reduce the total recurrence/metastasis rate, especially that of peritoneal metastasis. In the subgroup analysis, DFS and OS were both superior in deficient mismatch repair (dMMR) patients than in proficient MMR (pMMR) patients.
\end{abstract}

Conclusion: This hypothesis-generating study indicates that CHIP might be feasible for gastric cancer patients after D2 resection.

Keywords: Chemotherapeutic hyperthermic intraperitoneal perfusion, Hyperthermia, Peritoneal metastasis, Microsatellite instability, Gastric cancer

\footnotetext{
*Correspondence: mashenglin@medmail.com.cn; mashenglin@outlook.com; wu_zhibing@163.com

†Lucheng Zhu and Zhizheng Xu contributed equally to this work.

${ }^{2}$ Department of Oncology, Key Laboratory of Clinical Cancer Pharmacology and Toxicology Research of Zhejiang Province, Affiliated Hangzhou First

People's Hospital, Zhejiang University School of Medicine, Hangzhou 310006,

P.R. China

${ }^{5}$ Department of Oncology, Zhejiang Hospital, Hangzhou, Zhejiang 310013,

P.R. China

Full list of author information is available at the end of the article
}

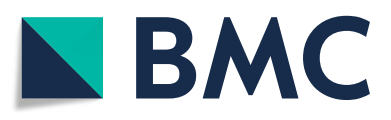

(- The Author(s). 2020 Open Access This article is licensed under a Creative Commons Attribution 4.0 International License, which permits use, sharing, adaptation, distribution and reproduction in any medium or format, as long as you give appropriate credit to the original author(s) and the source, provide a link to the Creative Commons licence, and indicate if changes were made. The images or other third party material in this article are included in the article's Creative Commons licence, unless indicated otherwise in a credit line to the material. If material is not included in the article's Creative Commons licence and your intended use is not permitted by statutory regulation or exceeds the permitted use, you will need to obtain permission directly from the copyright holder. To view a copy of this licence, visit http://creativecommons.org/licenses/by/4.0/. The Creative Commons Public Domain Dedication waiver (http://creativecommons.org/publicdomain/zero/1.0/) applies to the data made available in this article, unless otherwise stated in a credit line to the data. 


\section{Background}

Gastric cancer is a life-threatening disease, and each year nearly half of new cases occur in China [1]. After radical surgery, $20-50 \%$ of patients still experience peritoneal recurrence or failure $[2,3]$. Currently, there is no effective treatment for peritoneal metastasis (PM); therefore, exploration of a proper treatment becomes necessary to reduce or prevent peritoneal recurrence in those highrisk population.

Hyperthermic intraperitoneal chemotherapy (HIPEC) is a promising technique, and several studies have demonstrated its benefit in advanced gastric cancer $[4,5]$. HIPEC is also treated as a curative modality in digestive and primary PM $[6,7]$. The value of prophylactic HIPEC after D2 dissection is still unknown. GASTRICHIP is an ongoing phase 3 trial designed for prophylactic HIPEC (CHIP), but the results have not been reported [8]. We previously reported that CHIP could reduce peritoneal metastasis [9]. HIPEC could efficiently eliminate tumor cells and induce an anticancer immune response via heat shock protein 90 [10]. Moreover, emerging mechanisms on antitumor immune responses by hyperthermia have been studied, such as immune cells response, damage response of tumor cells, changes of tumor surface molecule and tumor vasculature, and exosomes release [11]. The mismatch repair (MMR) is a system function to keep DNA integrity and genomic stability [12]. Several studies have demonstrated that patients with a deficient MMR (dMMR) status will benefit from immunotherapy [13-15], as it is hypothesized that dMMR tumors can produce additional neoantigens to activate immune cells. In the present study, we address whether gastric cancer patients can benefit from CHIP after D2 dissection and explore the immunogenic effect of hyperthermia.

\section{Methods}

\section{Study population}

This was a retrospective study conducted in Hangzhou Cancer Hospital between Jul 1, 2018 and Dec 31, 2019. Eligibility criteria, as reported previously [9], mainly included histologically proven resectable gastric cancer after D2 dissection; stage IIA to IIIC; and patients received $\geq 2$ cycles chemotherapy with or without CHIP after surgery. All data/samples were fully anonymized before data processing and all patients agreed their medical records used in research.

\section{MMR protein assessment}

3-4 $\mu \mathrm{m}$ sections were prepared and stained for the following proteins (mutL homologue 1, MLH1; mutS homologue 2, MSH2; mutS homologue 6, MSH6; PMS1 homologue 2, PMS2). Immunohistochemical staining for hMSH2 (FE11, Calbiochem $^{\mathrm{\tau m}}$, Cambridge, Massachusetts, USA) and hMLH1 (G168-728, Pharmingen, San Diego, California, USA) was performed according to a previous publication [16]. Immunohistochemical staining for hMSH6 (EP49, Agilent Technologies, Santa Clara, CA) and hPMS2 (EP51, Agilent Technologies, Santa Clara, CA) was performed according to a previous publication [17]. Lymphocytes and normal epithelium served as positive internal controls. The definition of $\mathrm{dMMR}$ status was identical to previous publication [18].

\section{Treatment}

Each patient received treatment four to 6 weeks after surgery. Twenty-one patients received intravenous 5fluorouracil $\left(500 \mathrm{mg} / \mathrm{m}^{2}\right)$ and $\mathrm{LV}\left(200 \mathrm{mg} / \mathrm{m}^{2}\right)$ on days 1 to 5 , and intravenous cisplatin $\left(25 \mathrm{mg} / \mathrm{m}^{2}\right)$ on days 1 to 3 (IV group); the other 22 patients received the same dose of 5-fluorouracil and LV on days 1 to 5 , but with intraperitoneal cisplatin $\left(75 \mathrm{mg} / \mathrm{m}^{2}\right)$ on day 1 (CHIP group). The regimen was repeated every 3 weeks for no less than two cycles.

\section{CHIP procedure}

The procedure was carried out simultaneously on day 1 in the CHIP group. First, a Tenckhoff catheter was placed at McBurney's point. A total of $2000 \mathrm{ml}$ of $45^{\circ} \mathrm{C}$ heated physiological saline consisting of cisplatin (75 $\mathrm{mg} / \mathrm{m}^{2}$ ) was continuously irrigated into the abdominal space via the catheter for approximately $30 \mathrm{~min}$. The irrigated solution was absorbed by self-absorption. Abdominal regional radiofrequency hyperthermia was performed immediately after intraperitoneal perfusion with cisplatin via NRL-001 (Jilin Maida Co., Jilin, China) radiofrequency heating device. The intraperitoneal temperature was maintained at $42 \pm 0.5^{\circ} \mathrm{C}$ by real-time monitoring, and heating was continued for $60 \mathrm{~min}$.

\section{Efficacy and toxicity}

Disease-free survival (DFS, defined as interval between surgical resection to relapse) and overall survival (OS, defined as interval between surgical resection to the date of death or the date of the last follow-up) were evaluated. The adverse events were also evaluated (NCICTC $3.0)$.

\section{Analysis of immune cells in peripheral blood}

To analyze immune function, peripheral venous blood was obtained from patients before and after two cycles of chemotherapy or CHIP. Serum was aliquoted by centrifugation $(200 \times \mathrm{g}$ for $10 \mathrm{~min}$ ) at room temperature, and a flow cytometric assay was used to analyze the lymphocyte subpopulations.

\section{Statistical analysis}

The chi-square or Student's t test was chosen for different variables. Kaplan-Meier was used for survival analyses. Subgroup analyses were used to compare DFS and 
OS according to the MMR status, TNM stage, and treatment group. Data analyses were performed by IBM SPSS version 22.0 (IBM SPSS, Inc., Chicago, IL, USA) and figure presentations were performed by GraphPad Prism, Version 7.01 (GraphPad Software, Inc., San Diego, CA, USA). All tests were two sided and $P$ value $<0.05$ was considered significant.

\section{Results}

\section{Patient characteristics}

A total of 43 patients were finally included (Supplementary Fig. S1). By June 28, 2018, the median follow-up time was 58 months (range, 6 to 80 months). Of the 43 patients with surgically resected gastric cancer, 22 received CHIP treatment, and 21 patients received chemotherapy alone. The patient characteristics are shown in Table 1. Both groups had more male patients.

Table 1 Patient characteristics

\begin{tabular}{|c|c|c|c|}
\hline Item & $\begin{array}{l}\text { CHIP group } \\
(\boldsymbol{n}=22)\end{array}$ & $\begin{array}{l}\text { IV group } \\
(\boldsymbol{n}=21)\end{array}$ & $\boldsymbol{P}$ value \\
\hline Age (years), median & $51(38-69)$ & $55(43-68)$ & 0.552 \\
\hline Sex & & & 0.586 \\
\hline Male & 14 & 15 & \\
\hline Female & 8 & 6 & \\
\hline \multicolumn{4}{|l|}{ Comorbidities } \\
\hline Hypertension & 10 & 6 & 0.252 \\
\hline Hepatitis B & 2 & 2 & 1 \\
\hline Diabetes & 2 & 2 & 1 \\
\hline Chronic pulmonary disease & 3 & 4 & 0.689 \\
\hline Poststroke & 1 & 0 & \\
\hline Coronary heart disease & 1 & 1 & \\
\hline Pathological type & & & 0.804 \\
\hline Adenocarcinoma & 14 & 15 & \\
\hline Signet ring cell carcinoma & 6 & 5 & \\
\hline Mucinous adenocarcinoma & 2 & 1 & \\
\hline Stage & & & 0.876 \\
\hline$\|$ & 4 & 5 & \\
\hline$\| \mathrm{A}$ & 9 & 8 & \\
\hline IIIB & 6 & 4 & \\
\hline$\| \mathrm{IC}$ & 3 & 4 & \\
\hline MMR status & & & 0.729 \\
\hline $\mathrm{dMMR}$ & 4 & 3 & \\
\hline pMMR & 18 & 18 & \\
\hline Surgery mode & & & 0.658 \\
\hline Subtotal gastrectomy & 13 & 11 & \\
\hline Total gastrectomy & 9 & 10 & \\
\hline
\end{tabular}

CHIP chemotherapeutic hyperthermic intraperitoneal perfusion; IV chemotherapy alone; $d M M R$ deficient mismatch repair; $p M M R$ proficient mismatch repair
Adenocarcinoma was the major histology in both groups (CHIP: $n=14,63.3 \%$; IV; $n=15,71.4 \%$ ).

\section{Treatment outcomes}

DFS and OS were analyzed between the two regimens (Fig. 1). The median DFS time was 36.5 months in the CHIP group and 24.5 months in the IV group $(P=$ 0.044). The median OS time was not reached in the CHIP group and 33.1 months in the IV group $(P=$ 0.037). The benefit in terms of DFS and OS in CHIP patients was significantly superior to that in IV patients. In order to reduce confounding effect of MMR status on survival, a bivariate cox regression incorporating MMR status was analyzed, the hazard ratio of OS for CHIP was 0.443 (95\%CI: 0.201 to $0.978 ; p=0.044$ ) and the hazard ratio of DFS for CHIP was 0.518 (95\%CI: 0.264 to $1.017 ; p=0.056)$.

In the subgroup analysis, both DFS and OS were longer in dMMR patients than in proficient MMR (pMMR) patients (Fig. 2). In dMMR patients, the median DFS time was not reached, and the median OS time was 56.3 months, while in pMMR patients, the median DFS and OS times were 25.8 months and 33.1 months, respectively. To further assess the impact of the MMR status on hyperthermia, we separately analyzed the prognosis in $\mathrm{dMMR}$ and pMMR patients (Fig. 3). The median DFS and OS times of $\mathrm{dMMR}$ patients in the IV group were 42.1 and 51.6 months, while no dMMR patients who received CHIP show presented recurrence/metastasis or death at the last follow-up. For pMMR patients in the CHIP and IV groups, the median DFS times were 34.8 and 20.5 months, respectively $(P=0.184)$, and the median OS times were 37.4 and 24.1 months $(P=0.068)$, respectively.

\section{Lymphocyte subsets after treatment}

As previous studies have reported that hyperthermia could elicit antitumor immune responses, we determined different lymphocyte subsets before and after two cycles of treatment. As shown in Fig. 4, both CHIP and IV treatment could increase/decrease lymphocyte subsets. Compared with IV, CHIP significantly increased the numbers of total $\mathrm{T}$ cells and CD4+ T cells. In addition, the number of NK cells was also increased after CHIP, while the statistical value was marginally significant.

We observed a survival benefit and shifted lymphocyte subsets after CHIP. Therefore, we evaluated whether the survival benefit correlated with the changes in lymphocytes. The changes in lymphocyte subsets were divided by their median values. As shown in Fig. 5, the ratio of CD4 to CD8 $\mathrm{T}$ cells was significantly correlated with DFS $(P=0.020)$. In addition, the numbers of total T cells and CD8+ T cells had marginally significant correlations with DFS. 


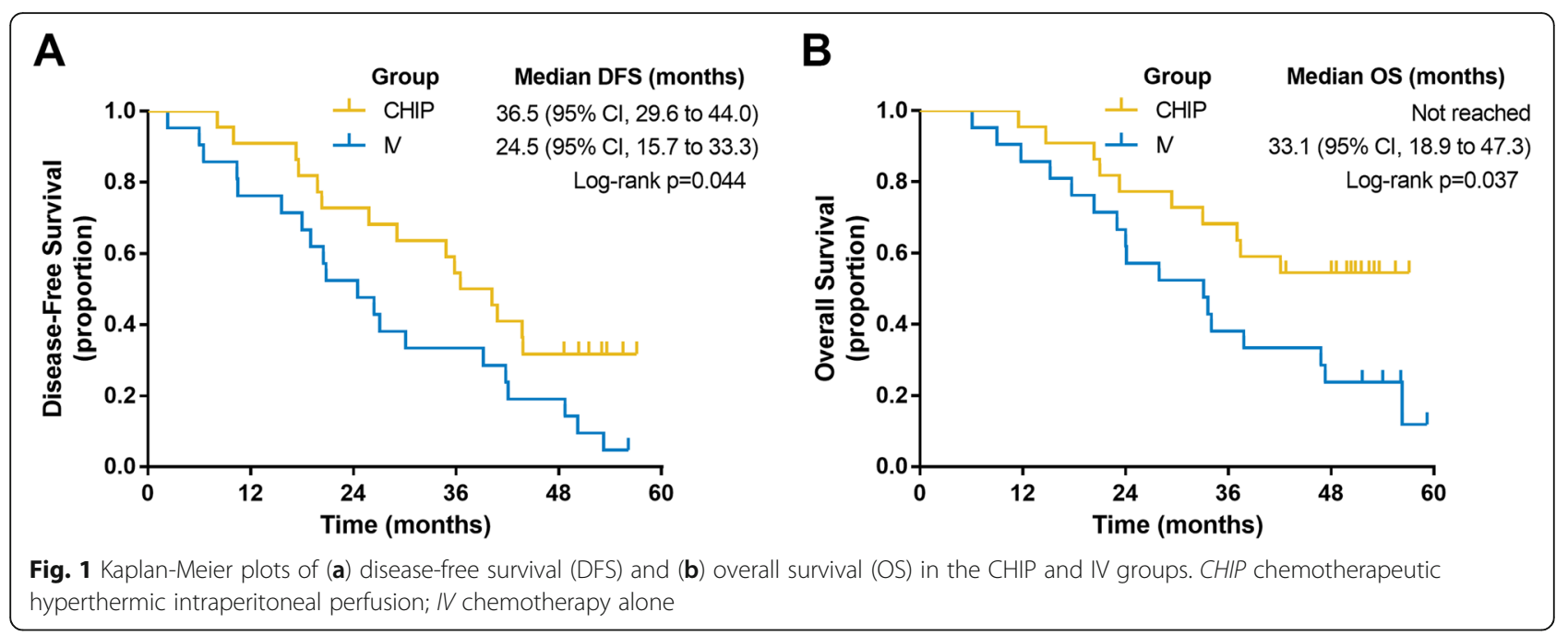

\section{Safety and tolerability}

The toxicity profiles were similar between the CHIP and IV groups. Details are listed in Table 2. Although myelosuppression occurred more frequently in the CHIP group, it did not reach statistical significance. There was no significantly difference between the two regimens with other grade $3 / 4$ events $(P>0.05$ for all variables). Interestingly, CHIP had a correlation with a more frequent incidence of grade $1 / 2$ trichomadesis $(P=0.021)$, while IV had a correlation with a more frequent incidence of grade $1 / 2$ chemical peritonitis $(P=0.048)$.

\section{Recurrence pattern}

As shown in Table 3, the most common recurrent or metastatic sites were remnant gastric metastasis, retroperitoneal lymph node metastasis, PM, and hepatic metastasis. 63.6\% (14 of 22) patients in the CHIP group experienced recurrence or metastases, while 90.5\% (19 of 21) patients in the IV group experienced recurrence or metastases $(P=0.037)$. PM $(4.5 \%$ vs. $33.3 \%)$ was less frequent in the CHIP group $(P=0.015)$. Hepatic metastasis $(9.1 \%$ vs. $23.8 \%)$ and seroperitoneum $(4.5 \%$ vs. $19.0 \%$ ) were also more frequent in the IV group, but there was no significant difference.

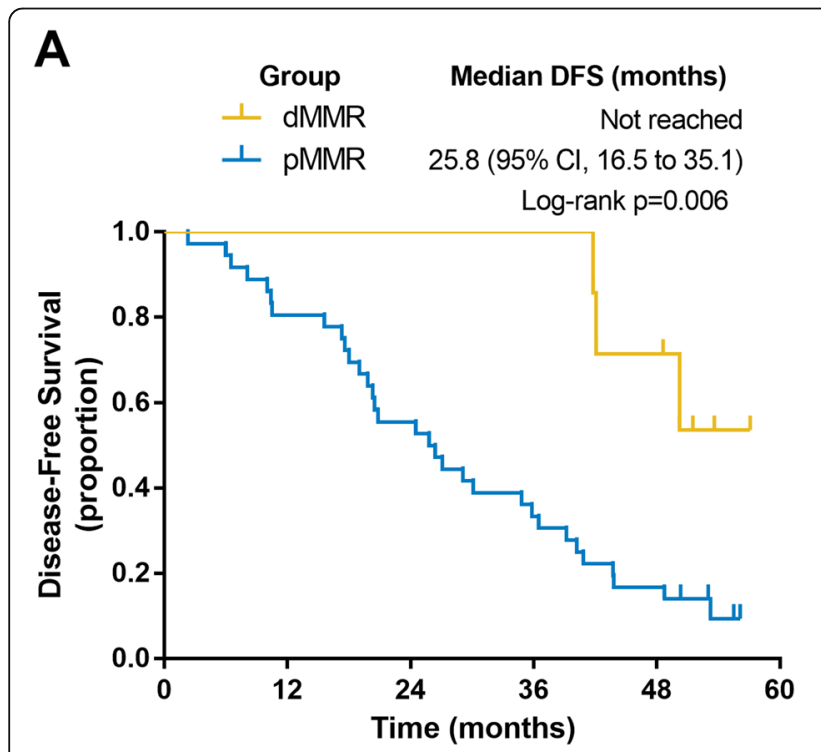

B

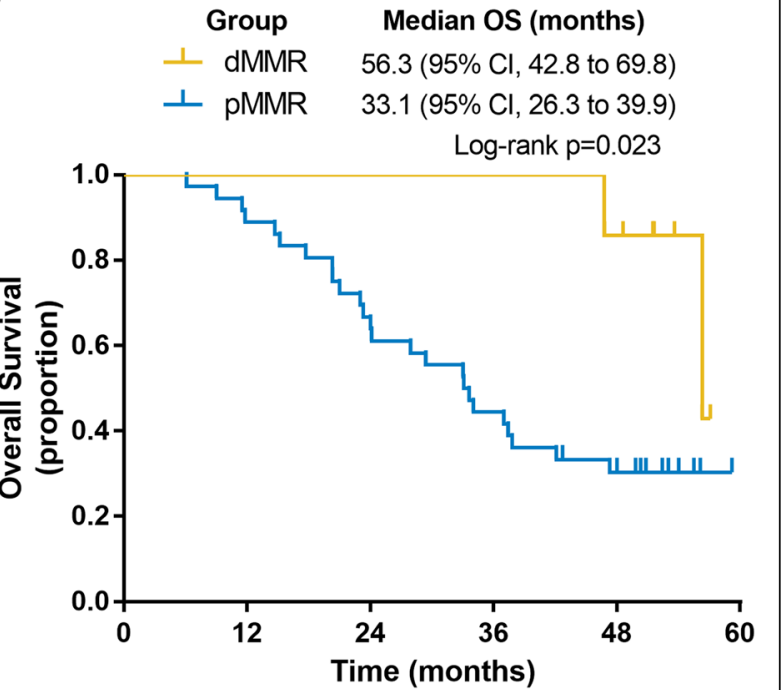

Fig. 2 Kaplan-Meier plots of (a) disease-free survival (DFS) and (b) overall survival (OS) in dMMR and pMMR patients. dMMR deficient mismatch repair; $p M M R$ proficient mismatch repair 
dMMR
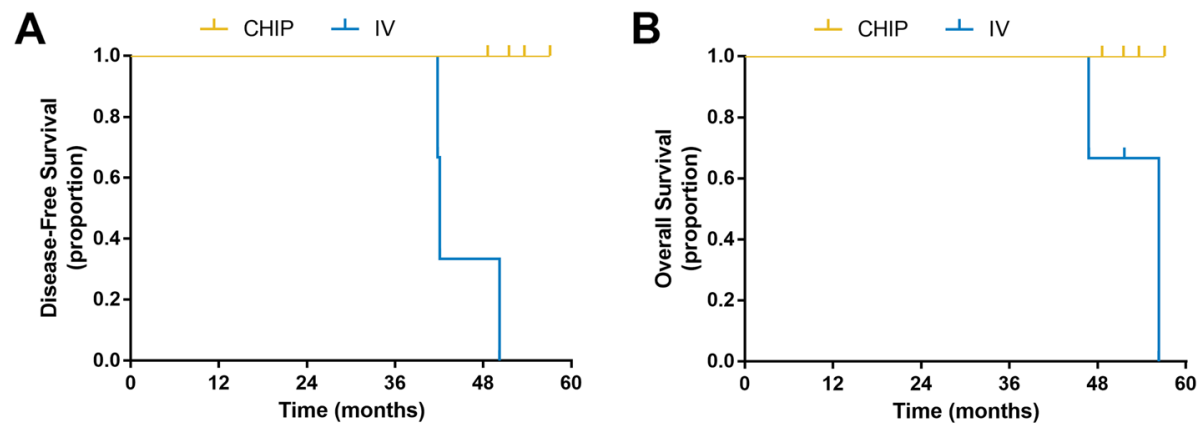

pMMR
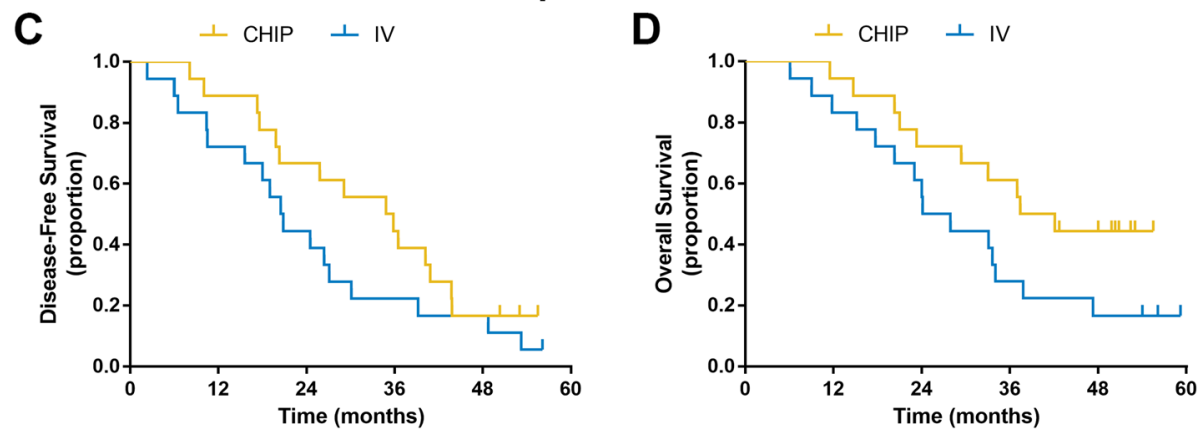

Fig. 3 Kaplan-Meier plots of (a, c) disease-free survival (DFS) and (b, d) overall survival (OS) in the CHIP and IV groups stratified by the MMR status. CHIP chemotherapeutic hyperthermic intraperitoneal perfusion; IV chemotherapy alone; dMMR deficient mismatch repair; pMMR proficient mismatch repair

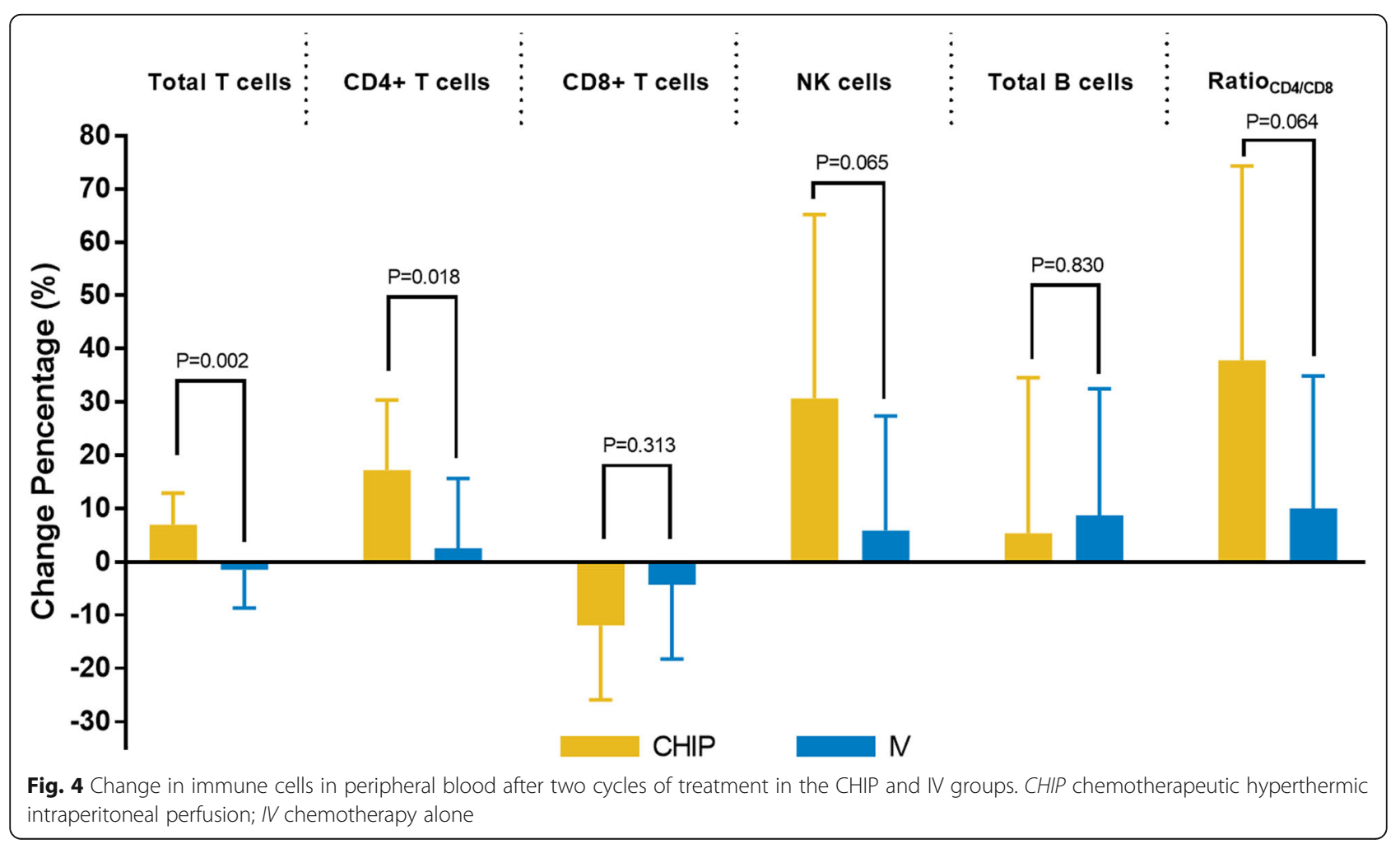




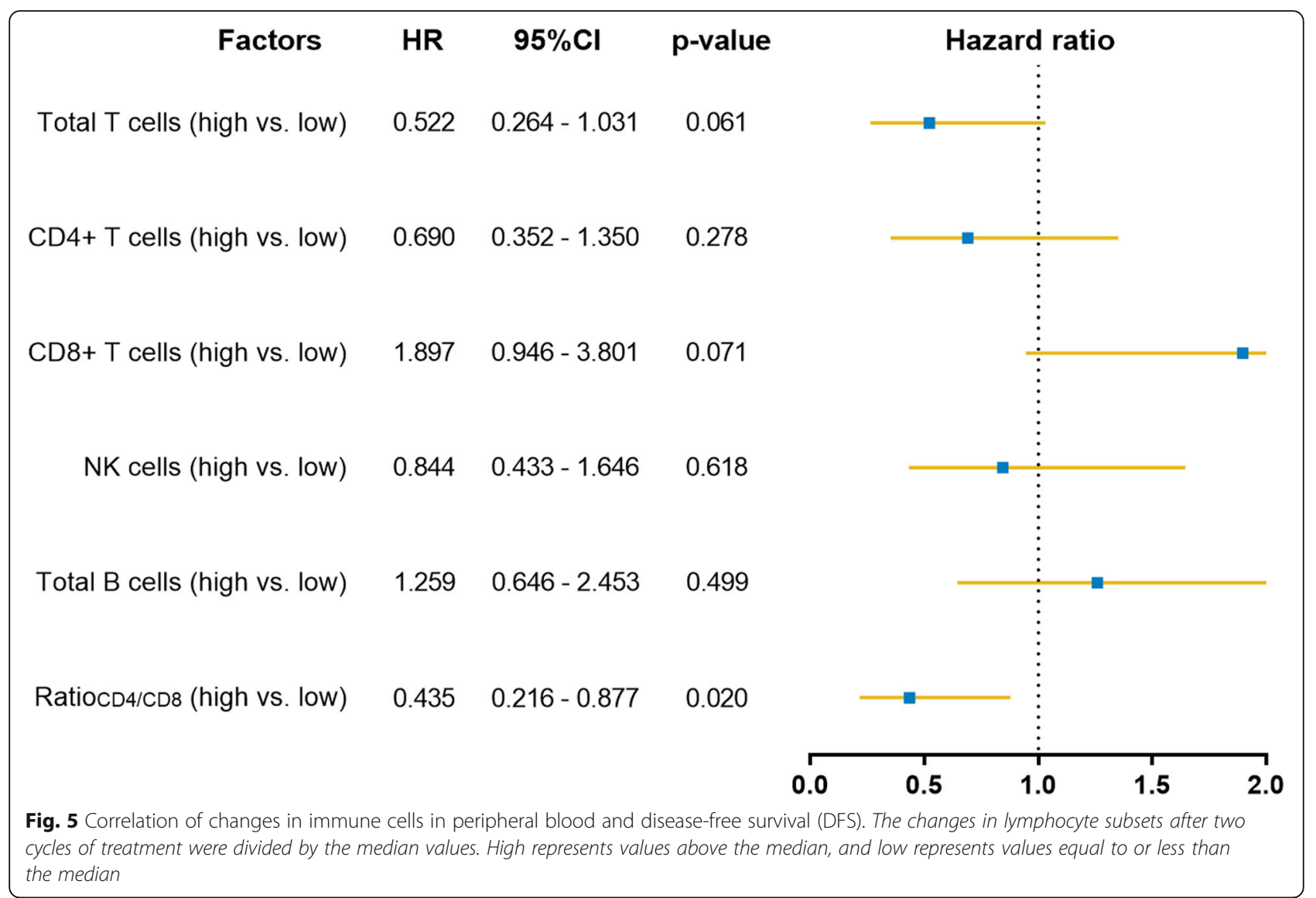

\section{Discussion}

In this study, we found that the median DFS and OS times were 36.5 months and more than 50 months, respectively, in the CHIP group, which were significantly longer than those in the IV group. We also found that CHIP could reduce the total recurrence/metastasis rate, especially peritoneal metastasis $(4.5 \%$ for the CHIP group and $33.3 \%$ for the IV group). In addition, in dMMR patients, the median DFS time was not reached and the OS time was 56.3 months, while in pMMR patients, the median DFS and OS times were 25.8 months and 33.1 months, respectively. Further analysis showed that dMMR patients might benefit from CHIP treatment.

Table 2 Toxicities related to treatment in the two groups

\begin{tabular}{|c|c|c|c|c|c|c|}
\hline \multirow[t]{2}{*}{ Adverse reaction } & \multicolumn{2}{|c|}{ CHIP group $(n=22)$} & \multicolumn{2}{|c|}{ IV group $(n=21)$} & \multicolumn{2}{|l|}{$\boldsymbol{P}$ value } \\
\hline & All grade & Grade 3/4 & All grade & Grade 3/4 & All grade & Grade 3/4 \\
\hline Leukocytopenia & 15 & 4 & 9 & 2 & 0.095 & 0.664 \\
\hline Anemia & 18 & 4 & 12 & 3 & 0.078 & 1.000 \\
\hline Thrombocytopenia & 15 & 7 & 10 & 2 & 0.172 & 0.132 \\
\hline Trichomadesis & 14 & 2 & 6 & 1 & 0.021 & 1.000 \\
\hline Liver dysfunction & 12 & 2 & 7 & 1 & 0.161 & 1.000 \\
\hline Renal dysfunction & 8 & 1 & 4 & 0 & 0.206 & 1.000 \\
\hline Cardiac dysfunction & 4 & 0 & 2 & 0 & 0.664 & - \\
\hline Nausea/vomiting & 18 & 3 & 12 & 2 & 0.078 & 1.000 \\
\hline Neurotoxicity & 9 & 0 & 5 & 0 & 0.232 & - \\
\hline Chemical peritonitis & 0 & 0 & 4 & 0 & 0.048 & - \\
\hline
\end{tabular}


Table 3 Recurrence or metastases after treatment

\begin{tabular}{llll}
\hline Recurrence or metastasis & CHIP group $(\mathrm{n}=22)$ & IV group $(\mathrm{n}=21)$ & $\boldsymbol{P}$ value \\
\hline Total & 14 & 19 & 0.037 \\
Remnant gastric metastasis & 5 & 5 & 0.933 \\
Retroperitoneal lymph node metastasis & 6 & 7 & 0.665 \\
Hepatic metastasis & 3 & 6 & 0.229 \\
Peritoneal metastasis & 1 & 4 & 0.021 \\
Seroperitoneum & 1 & 4 & 0.185 \\
\hline
\end{tabular}

CHIP chemotherapeutic hyperthermic intraperitoneal perfusion; IV chemotherapy alone

The high risk patients developing PM include those with tumors either extending beyond the serosa or that have invaded adjacent structures. Increasing data have shown the feasibility and efficacy of HIPEC in patients with PM [5, 19]; however, the role of CHIP remains inconclusive in patients without PM. A previous study showed that adding CHIP to neoadjuvant chemotherapy could further prolong OS (36 vs. 27 months) compared with neoadjuvant chemotherapy alone [20]. However, another study did not confirm the benefit of CHIP [21]. A recently published study showed that combination of HIPEC and cytoreductive surgery could prolong recurrence-free survival and OS, while it did not result in more side effects compared to surgery alone in ovarian cancer [22]. Our study showed that adding CHIP after D2 resection prolonged DFS and OS. Given these exciting results, CHIP could be used preventing serous cavity carcinomatosis in the future.

The MMR system is the crucial links in suppressing tumor formation and can repair mismatched DNA to keep genome stability [23]. Microsatellite instability (MSI) is reflective of a dMMR status and it can be measured by polymerase chain reaction (PCR) or immunohistochemistry (IHC). This study used IHC to identify MMR status, which could indirectly reflect MSI. MSI indicates the presence of short tandem repeats (commonly 1-6 base pairs) that spread throughout the genome and represents heteromorphosis associating with cancer development. A dMMR status is a positive prognostic factor for survival in patients with stage II colon cancer and might be a negative predictive factor for fluoropyrimidine contained regimens [24, 25]. However, a recent study showed that the dMMR remained a positive predictive factor in stage III colon cancer patients receiving FOLFOX regimen [26]. The role of a dMMR status in gastric cancer remains complicated. Smyth and colleagues performed an exploratory analysis of the MAGI $\mathrm{C}$ trial and found that a dMMR status and high MSI were associated with poor survival in patients receiving adjuvant chemotherapy [18]. Another study indicated that a dMMR status was associated with a favorable prognostic role in metastatic gastric cancer patients receiving first-line chemotherapy [27]. Our data showed that patients with a dMMR status had better DFS and OS than those with a pMMR status. A possible explanation for this finding might be that dMMR tumors have a powerful immune cells infiltrate, which could suppress invisible micrometastases after surgery $[28,29]$. Chemotherapy might have a negative effect on the body immunosurveillance, thus counteracting the innate benefit of the hypermutated phenotype [18]. In our study, almost all immune cells, including total $\mathrm{T}$ cells, CD4+ T cells, and NK cells, were elevated after chemotherapy (there was a minor decrease in CD8+ T cells).

Hyperthermia has been proven to sensitize tumor cells to radio- and chemotherapy and to modulate the immune system [30]. Previous studies have shown improved DFS and local tumor control without an increase in toxicity for the combined treatment. These findings may be partly due to the immunomodulatory function of hyperthermia that has been fully described by Zhang [31]. Fever-like hyperthermia activates both the innate and adaptive immune responses [32]. We also observed an elevation in $\mathrm{T}$ cells, CD4+ T cells, and NK cells in both the innate and adaptive immune systems after CHIP treatment. Cisplatin is widely used for the treatment of gastric cancer. It causes cell death through inhibiting and blocking DNA replication and transcription by forming various DNA adducts [33]. Besides inducing DNA damage, cisplatin can also efficiently activated the DNA damage response system [34]. Hyperthermia could enhance intracellular cisplatin accumulation and hamper DNA damage response. The combination of hyperthermia and intraperitoneal cisplatin can lead to an overall enhancement of drug cytotoxicity [35]. Another interesting finding was the different prognoses between $\mathrm{dMMR}$ and $\mathrm{pMMR}$ patients receiving CHIP. dMMR patients who received CHIP seemed to have better OS and DFS. Compared with pMMR tumors, dMMR tumors usually have an exceptionally higher mutational burden and neoantigen load, as well as more immune cells infiltration [36, 37]. Hyperthermia could activate both the innate and adaptive immune responses. Zunino's study showed that tumor-specific $\mathrm{T}$ cells were activated after tumor cells treated by HIPEC [10]. These data support the 
hypothesis that high mutant neoantigens in $\mathrm{dMMR}$ cancers make them sensitive to CHIP.

This study showed the benefit of adjuvant CHIP. While there were several limitations. This was a retrospective study with small sample size, especially those with a dMMR status. Some patients did not reach observed endpoint, which may have resulted in the efficacy of CHIP not being fully demonstrated.

\section{Conclusions}

We found that CHIP might offer a survival benefit and improved local control in patients with gastric cancer after D2 resection. A dMMR status seems to be a good predictive biomarker for prognosis, especially in patients with immunologically activated disease receiving CHIP. Because data from the present study are preliminary, further studies are is needed to confirm the clinical potential of CHIP in this population.

\section{Supplementary information}

Supplementary information accompanies this paper at https://doi.org/10. 1186/s12885-020-07339-6.

\section{Additional file 1.}

\section{Abbreviations}

PM: Peritoneal carcinomatosis; HIPEC: Hyperthermic intraperitoneal chemotherapy; CHIP: Prophylactic hyperthermic intraperitoneal chemotherapy; MMR: Mismatch repair; dMMR: deficient mismatch repair; PMMR: proficient mismatch repair; DFS: Disease-free survival; OS: Overall survival

\section{Acknowledgements}

We thank Yasi Xu and Kaicheng Pan for their work in data collection. This work was presented in ESMO 21st World Congress on Gastrointestinal Cancer [38].

\section{Authors' contributions}

Writing original draft and editing: LCZ, ZZX; Methodology and data acquisition: YJW, PYL, JNQ, SHY, BX, JJL; data analyses and interpretation: LCZ, ZBW; study concept and design, project administration: ZBW, SLM; Manuscript revision: LCZ, ZBW, SLM. All authors read and approved the final manuscript.

\section{Funding}

This study was supported by grants from KEY Project of Zhejiang Provincial Medicine and Health Science Foundation (2016ZDB011), Science and Technology Project of Hangzhou Bureau (2018A33 and 2015ZD01), and Zhejiang Natural Science Foundation (LGF18H160037 and LQ20H160020). The funders had no role in study design, data collection and analysis, decision to publish, or preparation of the manuscript.

\section{Availability of data and materials}

The datasets used and/or analyzed during the current study are available from the corresponding author on reasonable request.

\section{Ethics approval and consent to participate}

All procedures performed in studies involving human participants were in accordance with the ethical standards of the national research committee and with the 1964 Helsinki declaration and its later amendments or comparable ethical standards. The Scientific Research Board of Hangzhou Cancer Hospital approved this study (HZCH-2017-13). Administrative permissions were obtained to access the data used in this study. All patients signed the informed consent.

\section{Consent for publication}

All authors agreed publication of the manuscript

\section{Competing interests}

The authors have stated that they have no conflicts of interest.

\section{Author details}

${ }^{1}$ Department of Radiotherapy, Key Laboratory of Clinical Cancer Pharmacology and Toxicology Research of Zhejiang Province, Hangzhou Cancer Hospital, Hangzhou 310002, P.R. China. ${ }^{2}$ Department of Oncology, Key Laboratory of Clinical Cancer Pharmacology and Toxicology Research of Zhejiang Province, Affiliated Hangzhou First People's Hospital, Zhejiang University School of Medicine, Hangzhou 310006, P.R. China. ${ }^{3}$ Department of oncology, Changxing people's hospital, Huzhou 313100, P.R. China. ${ }^{4}$ The Second Clinical Medical College of Zhejiang Chinese Medical University, Hangzhou 310053, P.R. China. ${ }^{5}$ Department of Oncology, Zhejiang Hospital, Hangzhou, Zhejiang 310013, P.R. China. ${ }^{6}$ Department of Oncology, Jiande Second People's Hospital, Zhejiang 311604, P.R. China.

Received: 12 April 2020 Accepted: 25 August 2020

Published online: 31 August 2020

\section{References}

1. Chen W, Zheng R, Baade PD, Zhang S, Zeng H, Bray F, Jemal A, Yu XQ, He J. Cancer statistics in China, 2015. CA Cancer J Clin. 2016;66(2):115-32.

2. Liu D, Lu M, Li J, Yang Z, Feng Q, Zhou M, Zhang Z, Shen L. The patterns and timing of recurrence after curative resection for gastric cancer in China. World J Surg Oncol. 2016;14(1):305.

3. D'Angelica M, Gonen M, Brennan MF, Turnbull AD, Bains M, Karpeh MS Patterns of initial recurrence in completely resected gastric adenocarcinoma. Ann Surg. 2004;240(5):808-16.

4. Kuramoto M, Shimada S, Ikeshima S, Matsuo A, Yagi Y, Matsuda M, Yonemura $\mathrm{Y}, \mathrm{Baba} \mathrm{H}$. Extensive intraoperative peritoneal lavage as a standard prophylactic strategy for peritoneal recurrence in patients with gastric carcinoma. Ann Surg. 2009;250(2):242-6.

5. Yang XJ, Huang CQ, Suo T, Mei LJ, Yang GL, Cheng FL, Zhou YF, Xiong B, Yonemura Y, Li Y. Cytoreductive surgery and hyperthermic intraperitoneal chemotherapy improves survival of patients with peritoneal carcinomatosis from gastric cancer: final results of a phase III randomized clinical trial. Ann Surg Oncol. 2011;18(6):1575-81.

6. Elias D, Gilly F, Boutitie F, Quenet F, Bereder JM, Mansvelt B, Lorimier G, Dube $\mathrm{P}$, Glehen O. Peritoneal colorectal carcinomatosis treated with surgery and perioperative intraperitoneal chemotherapy: retrospective analysis of 523 patients from a multicentric French study. J Clin Oncol. 2010;28(1):63-8.

7. Yan TD, Deraco M, Baratti D, Kusamura S, Elias D, Glehen O, Gilly FN, Levine EA, Shen P, Mohamed F, et al. Cytoreductive surgery and hyperthermic intraperitoneal chemotherapy for malignant peritoneal mesothelioma: multi-institutional experience. J Clin Oncol. 2009:27(36):6237-42.

8. Glehen O, Passot G, Villeneuve L, Vaudoyer D, Bin-Dorel S, Boschetti G, Piaton E, Garofalo A. GASTRICHIP: D2 resection and hyperthermic intraperitoneal chemotherapy in locally advanced gastric carcinoma: a randomized and multicenter phase III study. BMC Cancer. 2014;14:183.

9. Zhu L, Xu Y, Shan Y, Zheng R, Wu Z, Ma S. Intraperitoneal perfusion chemotherapy and whole abdominal hyperthermia using external radiofrequency following radical D2 resection for treatment of advanced gastric cancer. Int J Hyperth. 2019;36(1):403-7.

10. Zunino B, Rubio-Patino C, Villa E, Meynet O, Proics E, Cornille A, Pommier S, Mondragon L, Chiche J, Bereder JM, et al. Hyperthermic intraperitoneal chemotherapy leads to an anticancer immune response via exposure of cell surface heat shock protein 90. Oncogene. 2016;35(2):261-8.

11. Toraya-Brown S, Fiering S. Local tumour hyperthermia as immunotherapy for metastatic cancer. Int J Hyperth. 2014;30(8):531-9.

12. Modrich P. Mechanisms in eukaryotic mismatch repair. J Biol Chem. 2006; 281(41):30305-9.

13. Overman MJ, Lonardi S, Wong KYM, Lenz HJ, Gelsomino F, Aglietta M, Morse MA, Van Cutsem E, McDermott R, Hill A, et al. Durable clinical benefit with Nivolumab plus Ipilimumab in DNA mismatch repair-deficient/ microsatellite instability-high metastatic colorectal Cancer. J Clin Oncol. 2018;36(8):773-9.

14. Overman MJ, McDermott R, Leach $J$ L, Lonardi S, Lenz HJ, Morse MA, Desai J Hill A, Axelson M, Moss RA, et al. Nivolumab in patients with metastatic 
DNA mismatch repair-deficient or microsatellite instability-high colorectal cancer (CheckMate 142): an open-label, multicentre, phase 2 study. Lancet Oncol. 2017;18(9):1182-91.

15. Le DT, Durham JN, Smith KN, Wang H, Bartlett BR, Aulakh LK, Lu S, Kemberling $H$, Wilt C, Luber BS, et al. Mismatch repair deficiency predicts response of solid tumors to PD-1 blockade. Science. 2017;357(6349):409-13.

16. Rigau V, Sebbagh N, Olschwang S, Paraf F, Mourra N, Parc Y, Flejou JF. Microsatellite instability in colorectal carcinoma. The comparison of immunohistochemistry and molecular biology suggests a role for hMSH6 [correction of hMLH6] immunostaining. Arch Pathol Lab Med. 2003;127(6): 694-700.

17. Mishima S, Kawazoe A, Nakamura Y, Sasaki A, Kotani D, Kuboki Y, Bando H, Kojima T, Doi T, Ohtsu A, et al. Clinicopathological and molecular features of responders to nivolumab for patients with advanced gastric cancer. J Immunother Cancer. 2019;7(1):24.

18. Smyth EC, Wotherspoon A, Peckitt C, Gonzalez D, Hulkki-Wilson S, Eltahir Z, Fassan M, Rugge M, Valeri N, Okines A, et al. Mismatch repair deficiency, microsatellite instability, and survival: an exploratory analysis of the Medical Research Council adjuvant gastric Infusional chemotherapy (MAGIC) trial. JAMA Oncol. 2017;3(9):1197-203.

19. Ellison LM, Man Y, Stojadinovic A, Xin H, Avital I. Cytoreductive surgery and hyperthermic intraperitoneal chemotherapy in treatment of gastric cancer with peritoneal carcinomatosis. Chin J Cancer Res. 2017;29(1):86-92.

20. Cui HB, Ge HE, Bai XY, Zhang W, Zhang YY, Wang J, Li X, Xing LP, Guo SH, Wang ZY. Effect of neoadjuvant chemotherapy combined with hyperthermic intraperitoneal perfusion chemotherapy on advanced gastric cancer. Exp Ther Med. 2014;7(5):1083-8.

21. Huang O, Lu X, Xu X, Shi Y. Fibrin-sealant-delivered cisplatin chemotherapy versus cisplatin hyperthermic intraperitoneal perfusion chemotherapy for locally advanced gastric cancer without peritoneal metastases: a randomized phase-II clinical trial with a 40-month follow-up. Cell Biochem Biophys. 2015;71(2):1171-80.

22. van Driel WJ, Koole SN, Sikorska K. Schagen van Leeuwen JH, Schreuder HWR, Hermans RHM, de Hingh I, van der Velden J, arts HJ, Massuger L et al: Hyperthermic Intraperitoneal chemotherapy in ovarian Cancer. N Engl J Med. 2018:378(3):230-40.

23. Ryan E, Sheahan K, Creavin B, Mohan HM, Winter DC. The current value of determining the mismatch repair status of colorectal cancer: a rationale for routine testing. Crit Rev Oncol Hematol. 2017;116:38-57.

24. Ribic CM, Sargent DJ, Moore MJ, Thibodeau SN, French AJ, Goldberg RM, Hamilton SR, Laurent-Puig P, Gryfe R, Shepherd LE, et al. Tumor microsatellite-instability status as a predictor of benefit from fluorouracilbased adjuvant chemotherapy for colon cancer. N Engl J Med. 2003;349(3) 247-57.

25. Sargent DJ, Marsoni S, Monges G, Thibodeau SN, Labianca R, Hamilton SR French AJ, Kabat B, Foster NR, Torri V, et al. Defective mismatch repair as a predictive marker for lack of efficacy of fluorouracil-based adjuvant therapy in colon cancer. J Clin Oncol. 2010;28(20):3219-26.

26. Zaanan A, Shi Q, Taieb J, Alberts SR, Meyers JP, Smyrk TC, Julie C, Zawadi A, Tabernero J, Mini E, et al. Role of deficient DNA mismatch repair status in patients with stage III Colon Cancer treated with FOLFOX adjuvant chemotherapy: a pooled analysis from 2 randomized clinical trials. JAMA Oncol. 2018:4(3):379-83.

27. Giampieri R, Maccaroni E, Mandolesi A, Del Prete M, Andrikou K, Faloppi L, Bittoni A, Bianconi M, Scarpelli M, Bracci R, et al. Mismatch repair deficiency may affect clinical outcome through immune response activation in metastatic gastric cancer patients receiving first-line chemotherapy. Gastric Cancer. 2017;20(1):156-63.

28. Grogg KL, Lohse CM, Pankratz VS, Halling KC, Smyrk TC. Lymphocyte-rich gastric cancer: associations with Epstein-Barr virus, microsatellite instability histology, and survival. Mod Pathol. 2003;16(7):641-51.

29. Chiaravalli AM, Feltri M, Bertolini V, Bagnoli E, Furlan D, Cerutti R, Novario R, Capella C. Intratumour T cells, their activation status and survival in gastric carcinomas characterised for microsatellite instability and Epstein-Barr virus infection. Virchows Arch. 2006;448(3):344-53.

30. Schildkopf P, Ott OJ, Frey B, Wadepohl M, Sauer R, Fietkau R, Gaipl US. Biological rationales and clinical applications of temperature controlled hyperthermia--implications for multimodal cancer treatments. Curr Med Chem. 2010;17(27):3045-57.

31. Zhang HG, Mehta K, Cohen P, Guha C. Hyperthermia on immune regulation: a temperature's story. Cancer Lett. 2008;271(2):191-204.
32. Frey B, Weiss EM, Rubner Y, Wunderlich R, Ott OJ, Sauer R, Fietkau R, Gaip US. Old and new facts about hyperthermia-induced modulations of the immune system. Int J Hyperth. 2012;28(6):528-42.

33. Jordan P, Carmo-Fonseca M. Molecular mechanisms involved in cisplatin cytotoxicity. Cell Mol Life Sci. 2000;57(8-9):1229-35.

34. Wang D, Lippard SJ. Cellular processing of platinum anticancer drugs. Nat Rev Drug Discov. 2005;4(4):307-20

35. Hettinga JV, Konings AW, Kampinga $\mathrm{HH}$. Reduction of cellular cisplatin resistance by hyperthermia--a review. Int J Hyperth. 1997;13(5):439-57.

36. Llosa NJ, Cruise M, Tam A, Wicks EC, Hechenbleikner EM, Taube JM, Blosser $\mathrm{RL}$, Fan $\mathrm{H}$, Wang $\mathrm{H}$, Luber $\mathrm{BS}$, et al. The vigorous immune microenvironment of microsatellite instable colon cancer is balanced by multiple counter-inhibitory checkpoints. Cancer Discov. 2015;5(1):43-51.

37. Saeterdal I, Bjorheim J, Lislerud K, Gjertsen MK, Bukholm IK, Olsen OC, Nesland JM, Eriksen JA, Moller M, Lindblom A, et al. Frameshift-mutationderived peptides as tumor-specific antigens in inherited and spontaneous colorectal cancer. Proc Natl Acad Sci U S A. 2001:98(23):13255-60.

38. Zhu L, Wu Z, Ma S. P-019 - Chemotherapeutic hyperthermic intraperitoneal perfusion following radical D2 resection in the treatment of advanced gastric cancer. Ann Oncol. 2019;30:iv5-6.

\section{Publisher's Note}

Springer Nature remains neutral with regard to jurisdictional claims in published maps and institutional affiliations.
Ready to submit your research? Choose BMC and benefit from:

- fast, convenient online submission

- thorough peer review by experienced researchers in your field

- rapid publication on acceptance

- support for research data, including large and complex data types

- gold Open Access which fosters wider collaboration and increased citations

- maximum visibility for your research: over $100 \mathrm{M}$ website views per year

At $\mathrm{BMC}$, research is always in progress.

Learn more biomedcentral.com/submissions 